\section{Content filtering human speech: A simple electronic system*}

\section{PETER L. ROGERS, KLAUS R. SCHERER $\nmid$, and ROBERT ROSENTHAL Harvard University, Cambridge, Massachusetts 02138}

The use of electronic bandpass filtering for content-masking speech samples in studies on expressive aspects of vocal behavior is discussed. A simple electronic filtering system, which can be built easily and which can be adopted readily for a variety of applications, is described.

In recent years researchers in the area of nonverbal communication have shown renewed interest in the indicative and communicative functions (Ekman \& Friesen, 1968) of extralinguistic aspects of human speech (Mahl \& Schulze, 1964). Specifically, attempts have been made to assess how much information about a speaker's more enduring personality traits and transitory emotional states may be conveyed by such paralinguistic phenomena as intonation, rhythm, tempo, and volume. One important aspect of the

*Preparation of this report and some of the work described herein was supported by Research Grants GS-1741 and GS-2654 from the Division of Social Sciences of the National Science Foundation.

+Now at the Department of Psychology, University of Pennsylvania, Philadelphia, Pennsylvania 19104. research procedure has been to isolate the paralinguistic channel of communication by eliminating or controlling for semantic content in the verbal or linguistic channel. A variety of methods has been used. In some cases, the speaker reads "standard content" passages or such "meaningless content" as the alphabet. Other cases have included the use of foreign-language speakers, playing back speech backwards from a tape recorder, and, most recently, randomized splicing of recording tape containing a speech sample (Scherer ${ }^{1}$ ). More detailed descriptions of these methods and summaries of the relevant studies can be found in Kramer (1963), Starkweather (1967), Duncan (1969), and Scherer (1970).

A method that has been used quite frequently and rather successfully in studies on the nonverbal communication of emotional expression is "electronic content filtering." With the help of commercial bandpass filters, voice frequencies above $400-600 \mathrm{~Hz}$ are removed, which renders the respective speech sample unintelligible, as speech comprehension depends heavily on these higher frequencies (Fletcher, 1953; Licklider \& Miller, 1951). The result of this filtering process sounds like "a kind of mumble as though heard through a wall [Starkweather, 1956]." The effect of this procedure on voice characteristics is not clear (Kramer, 1963; Scherer $^{1}$ ); there is little doubt, however, that a large number of speech characteristics, such as intonation contours, rhythm, tempo, and continuity, are still discernible.

Investigators have found that untrained judges could differentiate or identify emotional states (Soskin \& Kauffman, 1961; Alpert, Kurtzberg, \& Friedhoff, 1963; Kramer, 1964), pathological personality development (Starkweather, 1956; Cohen, 1961), and normal personality traits (Milmoe, 1965) on the basis of listening to content-filtered speech samples. In two recent studies, content-filtered speech samples were used to postdict doctors'. successes in referring alcoholic patients for treatment and to relate aspects of babies' behaviors to their mothers' voices (Milmoe et al, 1967; Milmoe et al, 1968).

some investigators have found it

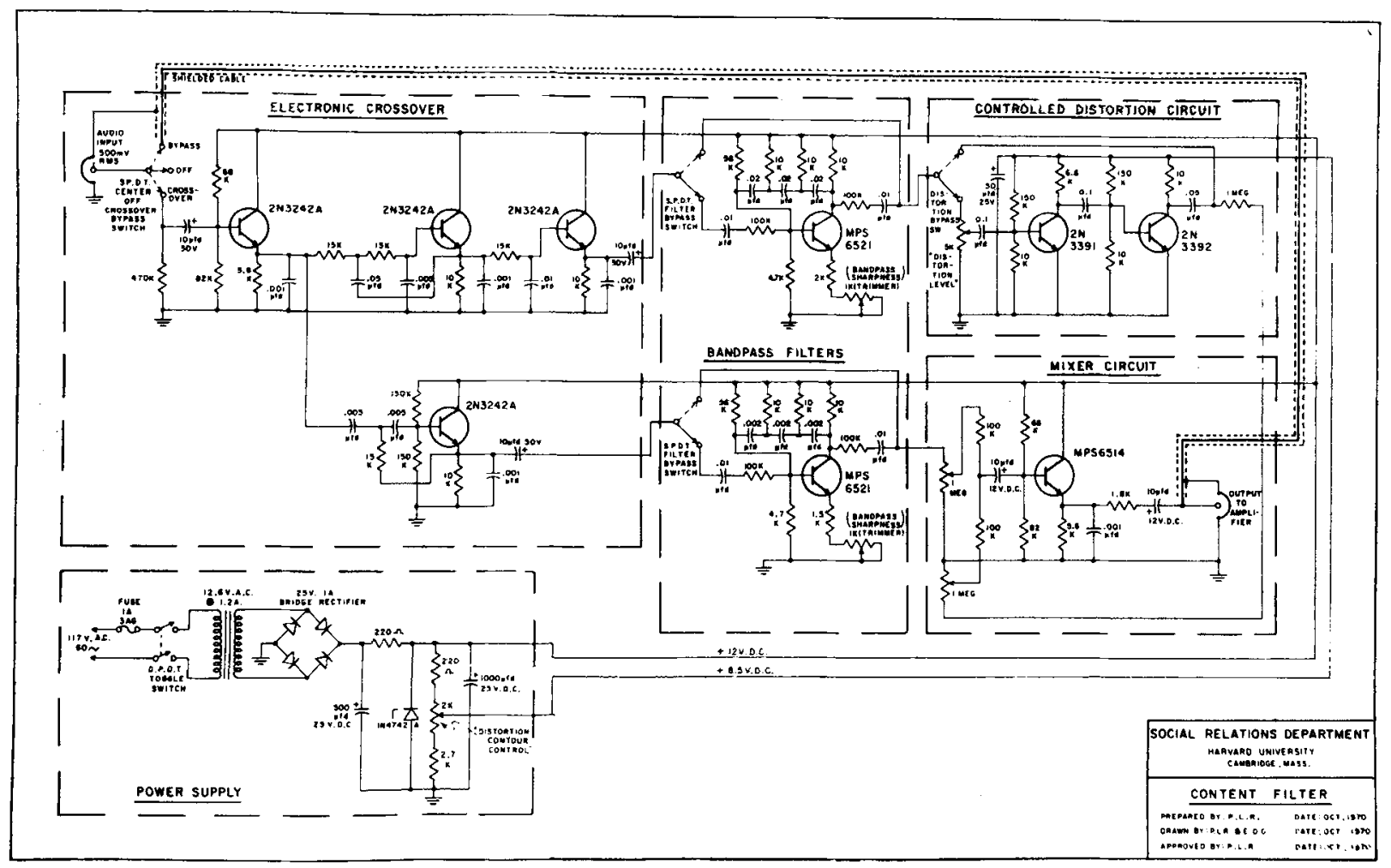

Fig. 1. Schematic diagram of a content-filtering system. 


\begin{tabular}{|c|c|c|c|c|c|c|}
\hline Quantity & Type & \multicolumn{4}{|c|}{ Description } & $\begin{array}{c}\text { Net } \\
\text { Each }\end{array}$ \\
\hline & & \multicolumn{4}{|c|}{ Semiconductors } & \\
\hline 4 & $2 \mathrm{~N} 3242 \mathrm{~A}$ & \multicolumn{4}{|c|}{ RCA Transistor } & $\$ .83$ \\
\hline 2 & MPS-6521 & \multicolumn{4}{|c|}{ Motorola Transistor } & .90 \\
\hline 1 & MPS-6514 & \multicolumn{4}{|c|}{ Motorola Transistor } & .60 \\
\hline 1 & $2 N 3391$ & \multicolumn{4}{|c|}{ G.E. Transistor } & .61 \\
\hline 1 & $2 \mathrm{~N} 3392$ & \multicolumn{4}{|c|}{ G.E. Transistor } & .29 \\
\hline 1 & $1 \mathrm{~N} 4742 \mathrm{~A}$ & \multicolumn{4}{|c|}{ Motorola Zener Diode } & 1.93 \\
\hline 1 & MDA-920-1 & \multicolumn{4}{|c|}{ Motorola Bridge Rectifier } & 1.42 \\
\hline & & \multicolumn{4}{|c|}{ Capacitors } & \\
\hline 5 & TE-1304 & \multicolumn{4}{|c|}{ Sprague 10 microfarad $50 \mathrm{~V}$ Electroly tic* } & .63 \\
\hline 2 & TE-1128 & \multicolumn{4}{|c|}{ Sprague 10 microfarad $12 \mathrm{~V}$ Electrolytic } & .57 \\
\hline 1 & TE-1 209 & \multicolumn{4}{|c|}{ Sprague 50 microfarad $25 \mathrm{~V}$ Electrolytic } & .81 \\
\hline 1 & $39 \mathrm{D} 507 \mathrm{G025 \textrm {HE }} 4$ & \multicolumn{4}{|c|}{ Sprague 500 microfarad $25 \mathrm{~V}$ Electrolytic } & 1.74 \\
\hline 1 & $39 \mathrm{D} 108 \mathrm{G0} 25 \mathrm{GL} 4$ & \multicolumn{4}{|c|}{ Sprague 1000 microfarad $25 \mathrm{~V}$ Electrolytic } & 1.95 \\
\hline 2 & $5 \mathrm{HK} \cdot \mathrm{P} 10$ & \multicolumn{4}{|c|}{ Sprague 0.1 microfarad Ceramic } & .54 \\
\hline 5 & 5GA-S10 & Sprague 0.0 & micr & ad Cer & & .15 \\
\hline 5 & $5 \mathrm{GA}-\mathrm{D} 10$ & Sprague 0.0 & $1 \mathrm{mic}$ & $\operatorname{arad} \mathrm{Ce}$ & & .15 \\
\hline 2 & $5 \mathrm{HK}-\mathrm{S5O}$ & Sprague 0.0 & $\mathrm{micr}$ & ad Cer & & .27 \\
\hline 3 & $5 \mathrm{GA}-\mathrm{S} 20$ & Sprague 0. & micr & ad Cer & & .15 \\
\hline 3 & $5 \mathrm{GA}-\mathrm{D} 20$ & Sprague 0.0 & $2 \mathrm{mic}$ & $\operatorname{arad} \mathrm{Ce}$ & & .15 \\
\hline 3 & 5GA-D50 & Sprague 0.0 & $5 \mathrm{mic}$ & $\operatorname{arad} \mathrm{Ce}$ & & .15 \\
\hline & & & & rs & & \\
\hline 2 & & $68 \mathrm{~K}$ & $\mathrm{~L} / 2 \mathrm{~W}$ & $10 \%$ & Carbon & .12 \\
\hline 2 & & $82 \mathrm{~K}$ & $1 / 2 W$ & $10 \%$ & Carbon & .12 \\
\hline 1 & & $470 \mathrm{~K}$ & $1 / 2 W$ & $10 \%$ & Carbon & .12 \\
\hline 2 & & $5.6 \mathrm{~K}$ & $1 / 2 W$ & $10 \%$ & Carbon & .12 \\
\hline 4 & & $15 \mathrm{~K}$ & $1 / 2 W$ & $10 \%$ & Carbon & .12 \\
\hline 12 & & $10 \mathrm{~K}$ & $1 / 2 W$ & $10 \%$ & Carbon & .12 \\
\hline 2 & & $56 \mathrm{~K}$ & $1 / 2 \mathrm{~W}$ & $10 \%$ & Carbon & .12 \\
\hline 6 & & $100 \mathrm{~K}$ & $1 / 2 W$ & $10 \%$ & Carbon & .12 \\
\hline 2 & & $4.7 \mathrm{~K}$ & $1 / 2 W$ & $10 \%$ & Carbon & .12 \\
\hline 1 & & $2.0 \mathrm{~K}$ & $1 / 2 W$ & $10 \%$ & Carbon & .12 \\
\hline 4 & & $150 \mathrm{~K}$ & $1 / 2 W$ & $10 \%$ & Carbon & .12 \\
\hline 1 & & $6.8 \mathrm{~K}$ & $1 / 2 W$ & $10 \%$ & Carbon & .12 \\
\hline 1 & & 1 megohm & $1 / 2 W$ & $10 \%$ & Carbon & .12 \\
\hline 1 & & $1.5 \mathrm{~K}$ & $1 / 2 W$ & $10 \%$ & Carbon & .12 \\
\hline 1 & & $1.8 \mathrm{~K}$ & $1 / 2 W$ & $10 \%$ & Carbon & .12 \\
\hline 2 & & $220 \mathrm{ohms}$ & $1 / 2 W$ & $10 \%$ & Carbon & .12 \\
\hline 1 & & $2.7 \mathrm{~K}$ & $1,2 \mathrm{~W}$ & $10 \%$ & Carbon & .12 \\
\hline 2 & CMU-1052 & Ohmite & $1 \mathrm{me}$ & m Pote & ometer & 1.95 \\
\hline 1 & CMU -5021 & Ohmite & $5 \mathrm{KP}$ & atiome & & 1.95 \\
\hline 1 & WW-202 & Centralab & $2 \mathrm{~K} \mathrm{P}$ & atiome & & 1.32 \\
\hline 2 & MTC-1 3L 4 & Mallory & $1 \mathrm{~K} \mathrm{~T}$ & mers & & .39 \\
\hline & & & iscella & as Par & & \\
\hline 2 & 3501-FP & Switchcraft & ehono & & & .21 \\
\hline 2 & $71-201$ & Vero Board & & & & .60 \\
\hline 1 & 7203 & $C \& K$ D.P. & .T. Ce & Off $S$ & & 2.55 \\
\hline 2 & MST-215N & Alco D.P.D & T. Swi & & & 2.20 \\
\hline 1 & MST-115D & Alco S.P.D & $\therefore$ Swit & & & 1.70 \\
\hline 1 & $\mathrm{CU}-2107 \mathrm{~A}$ & Bud Mini B & & & & 1.80 \\
\hline 1 & $273-1505$ & Radio Shac & Trans & mer & & 2.10 \\
\hline 1 & 83050 & Arrow-Hart & Power & itch & & .83 \\
\hline 4 & 2194 & H. H. Smit & Rubb & eet & & .03 \\
\hline 1 & $17109-\mathrm{SPT}$ & Belden Lin & Cord & & & .45 \\
\hline 1 & 938 & H. 11. Smit & Strain & lief & & .04 \\
\hline 1 & $342014 \mathrm{~A}$ & Littlefuse $H$ & older & & & .41 \\
\hline 1 & 312001 & Littlefuse 1 & $3 \mathrm{AG}$ & & & .08 \\
\hline 4 & $407 \mathrm{R} 2 \mathrm{~K} 1$ & Raytheon & nobs & & & .39 \\
\hline
\end{tabular}

* Two of these capacitors are not shown on the schematic. One may be connected from the emitter of each MPS 6521 transistor to ground (positive to emitter) to increase filter gain.

difficult to have speech samples content-filtered in this manner. Frequently, commercial bandpass filters (such as Krohnhite Model $310 \mathrm{~A}-\mathrm{B})$ are not readily available and one has to rely on outside agencies for the filtering, which may result in the loss of the flexibility needed to achieve optimal results. For example, there is no difficulties and to enable researchers to use a simple content-filtering procedure that can be adjusted easily to fit specific needs, the following small system was developed. It can be built easily by an experienced electronics technician and can be used without any knowledge of electronic circuitry or the physics of sound production.

The equipment consists of a power supply, an electronic crossover, highand low-bandpass filters, a controlled distortion section, and a mixer-amplifier. The separate circuits are housed in a metal minibox, which mounts the input and output jacks, controls, and switches. The unit is plugged into any $117-\mathrm{V}$ ac house current outlet and is separately fused.

The system, a schematic diagram of which is shown in Fig. 1, is designed with maximum flexibility in mind, and all functions are continuously variable or may be switched out altogether through the use of bypass switches. In operation, the output of a tape deck or tape recorder, which is normally fed to an external amplifier, is connected to the input jack, and the unit is turned on. A system bypass switch allows the user to feed the signal directly to the output jack for setup or test purposes, and the filter has no effect on the signal. When this feature is not desired, the opposite position of the switch connects the input signal to the electronic crossover network. This circuit separates the input signal into high and low bands with a crossover frequency of approximately $650 \mathrm{~Hz}$.

The outputs of the crossover are fed to separate filter bypass switches, preceding the high- and low-bandpass filter circuits. The user has the option of using either filter or both simultaneously at this point, or he may bypass both bandpass filters, leaving the separate bands unaffected. The function of the bandpass filters is to select a very narrow band of frequencies of the high and/or low bands, respectively, which are passed, whereas frequencies outside of this range are attenuated, thus reducing to a bare minimum the frequencies on which speech intelligibility depends. The low-bandpass filter peaks at about $310 \mathrm{~Hz}$, the high filter around $3,400 \mathrm{~Hz}$.

The filtered signals are treated somewhat differently, depending on the band through which they have passed. The input signals of the high-bandpass filter are fed to one side of the mixer amplifier, where they may be combined with the low band frequencies to make up the final output signal desired. The output of the low-bandpass filter, however, is fed first to a bypass switch. This switch allows the user to direct the low-frequency signals to the mixer 
amplifier or to send them to a special circuit, the controlled distortion section. Since most of the intelligibility in the low-band signal can be eliminated with the low-bandpass filter, additional alterations are usually not needed.

Uccasionally, however, it is necessary to clip the peaks from the audio signal in order to reduce intelligibility further. The controlled distortion section allows the user to vary the degree of distortion as well as the "contour" of the resulting sound. "Contour" refers to the amount of amplification given the distorted signal before it is fed to the mixer-amplifier stage. This latter portion of the circuitry is designed to bring the output signal up to the original level of the input signal and allows the user to combine any amount of high frequencies with any amount of lows in making up the output signal. Thus, a certain amount of "fine tuning" can be carried out following the filters and distortion circuit to retain as much of the expressive content of the signal as possible while at the same time effectively removing speech intelligibility and, thus, semantic content.

This system can be used for various other purposes in research on vocal communication. Frequently, tape recordings need to be "cleaned up" by removing hum, air-conditioner noise, and other interference. This is achieved by filtering out those frequencies which make up the unwanted signal while passing as much of the desired sound as possible. Similarly, the device can be used for systematic manipulation of the perceived pitch characteristics of the speaker, e.g., by allowing only the high frequencies of the signal to reach the output.

Obviously, the content-filtering system described is relatively simple and does not attain the exacting standards of commercial bandpass filters. It does, however, effectively mask semantic content in speech samples and offers a high degree of flexibility to the psychological investigator whose research does not require too high a level of acoustic and electronic precision.

Table 1 provides a list of parts along with unit costs.

\section{REFERENCES}

ALPERT, M.. KURTZBERG, R. L., \& FRIEDHOFF, A. F. Transient voice changes associated with emotional stimuli. General Psychiatry, 1963, 8. 362-365.

COHEN, A. Estimating the degree of schizophrenic pathology from recorded interview samples. Journal of Clinical Psychology, 1961, 17, 403-406.

DUNCAN, S. Nonverbal communication. Psychological Bulletin, 1969, 72, 118-137.

EKMAN, P., \& FRIESEN, W. V. Non-verbal behavior in psychotherapy research. In J. Shlien (Ed.), Research in psychotherapy. Vol. 3. Washington, D.C: American Psychological Association, 1968.

FLETCHER, $\mathrm{H}$. Speech and hearing in communication. New York: Van Nostrand. 1953.

KRAMER, E. The judgment of personal characteristics and emotions from non-verbal properties of speech. Psychological Bulletin, 1963, 60, 408-420.

KRAMER, E. Elimination of verbal cues in judgments of emotion from voice. Journal of Abnormal \& Social Psychology, 1964, 68, 390-396.

LICKLIDER, J. C. R., \& MILLER, G. A.
The perception of speech. In S. S. Stevens (Ed.), Handbook of experimental psychology. New York: Wiley, 1951. Pp. 1040-1074.

MAHL, G. F., \& SCHULZE, G. Psychological research in the extralinguistic area. In T. A. Sebeok, A. S. Hays, and M. C. Bateson (Eds.), Approaches to semiotics. The Hague: Mouton, 1964. Pp. 51-124.

MILMOE, S. Characteristics of speakers and listeners as factors in nonverbal communication. Unpublished senior honors thesis, Harvard University, Department of Social Relations, 1965.

MILMOE, S., ROSENTHAL, R., BLANE, H., CHAFETZ, M., \& WOLF, I. The doctor's voice: Postdictor of successful referral of alcoholic patients. Journal of Abnormal Psychology, 1967, 72, 78-84.

MILMOE, S., NOVEY, M. S., KAGAN, J., \& ROSENTHAL, R. The mother's voice: Postdictor of aspects of her baby's behavior. Proceedings, 76th Annual Convention, APA, 1968, 463-464.

SCHERER, K. R, Techniken zur Mikro-Analyse Kommunikativer Verhaltensweisen. In J, Koolwijk (Ed.), Handbuch der Sozialforschung. Oldenbourg, 1970.

SOSKIN, W., \& KAUFFMAN, P. Judgment of emotion in word-free voice samples. Journal of Communication, 1961, 11 , 73-80.

STARKWEATHER, J. A. Content-free speech as a source of information about the speaker. Journal of Abnormal \& Social Psy chology, 1956, 52, 394-402.

STARKWEATHER, J. A. Vocal behavior as an information channel of speaker status. In $\mathrm{K}$. Salzinger and $\mathrm{S}$. Salzinger (Eds.), Research in verbal behavior and some neurophysiological implications. New York: Academic Press, 1967. Pp. 253-262.

\section{NOTE}

1. Scherer, K. R. Randomized splicing: A simple technique for masking speech content. Unpublished manuscript, Harvard University, 1970. 